Seção Temática: Os Recursos Públicos em Disputa

Volume 11 - $2021 \mid$ n. 27

\title{
Estratégias de Privatização da Educação Infantil em Ribeirão Preto e as Resistências
}

\author{
Bianca Correa \\ Universidade de São Paulo (USP), São Paulo/SP - Brasil \\ José Marcelino de Rezende Pinto \\ Universidade de São Paulo (USP), São Paulo/SP - Brasil \\ Teise de Oliveira Guaranha Garcia \\ Universidade de São Paulo (USP), São Paulo/SP - Brasil
}

\section{Resumo}

O artigo problematiza a privatização da gestão da educação infantil, bem como suas decorrências para o financiamento da educação. A opção política por assegurar o oferecimento de vagas na educação infantil por meio da transferência da gestão a diversas instâncias privadas é histórica no Brasil. Este texto, entretanto, tratará especificamente da transferência da gestão e do financiamento público a entidades privadas por meio de chamamentos públicos/editais e convites específicos para a escolha do ente privado a ser "parceiro" do poder público municipal e as consequências para a concretização do direito à educação infantil de qualidade. A fim de atingir os objetivos propostos, descreveuse e analisou-se o processo de privatização na gestão de creches a partir de 2019. O estudo indica clara intencionalidade da administração pública em se desonerar da gestão na educação infantil, privatizando até mesmo o segmento para o qual não há demanda reprimida.

Palavras-chave: Educação Infantil. Privatização. Financiamento da Educação. Gestão Educacional.

\section{Strategies for Privatization of Early Childhood Education in Ribeirão Preto and the Resistance}

\begin{abstract}
The article discusses the privatization of the management of early childhood education, as well as its consequences for the financing of education. The political option for ensuring the offer of places in early childhood education through the transfer of management to several private instances is historical in Brazil. This text, however, will specifically deal with the transfer of public management and financing to private entities through public calls/public notices and specific invitations to choose the private entity to be a "partner" of the municipal government and the consequences for the realization of the right to quality early childhood education. In order to achieve the proposed objectives, the privatization process in daycare management was described and analyzed from 2019 onwards. The study indicates a clear intention of the public administration to exempt itself from the management of early childhood education, privatizing even the segment for which there is no repressed demand.
\end{abstract}

Keywords: Early Childhood Education. Privatization. Education Financing. Educational Management. 
Estratégias de Privatização da Educação Infantil em Ribeirão Preto e as Resistências

\section{A oferta de educação infantil no Brasil: entre avanços e retrocessos}

Como vários pesquisadores e pesquisadoras já evidenciaram, é possível encontrar registros de instituições de educação destinadas a crianças com menos de sete anos no Brasil desde ao menos o século XIX. De cunho caritativo e voltados às crianças pobres ou abandonadas, os primeiros serviços tinham como característica "salvar" a criança pobre cuja família era vista como incapaz de se responsabilizar por ela. Foi assim com as Santas Casas e suas caixas dos expostos, recurso que permitia o abandono de bebês de forma relativamente discreta e que eram acolhidos permanecendo na instituição na condição de asilado. Já para crianças um pouco mais velhas e de famílias mais abastadas, foram criados os primeiros jardins de infância, cujos objetivos eram recrear e ensinar boas maneiras às crianças daquelas famílias. Ainda que houvesse grande diferença desde o início entre uma e outra instituição, e que os discursos da época apregoassem a necessidade de um atendimento de qualidade, ao longo do tempo essa diferença entre um e outro atendimento foi se acentuando. Durante muito tempo, a creche foi assegurada por cooperativas de organizações sociais situadas em bairros mais pobres ou mesmo favelas (CAMPOS, 1988) ou por meio de trabalho voluntário, vinculado ou não a igrejas.

A esse respeito, Moysés Kuhlmann Jr. (2000) relata a origem das creches como espaços destinados às crianças pobres, com a presença de discursos e programas nessa perspectiva desde o século XIX e destaca, entre outras iniciativas já nos anos 1960 do século XX, o papel do Fundo das Nações Unidas para a Infância (Unicef) na promoção de modelos que não apenas tivessem baixo custo, mas que contassem com a participação de igrejas de "diferentes denominações". É assim que, em 1965, durante a "Conferência Latino-Americana sobre a infância e a juventude no desenvolvimento Nacional", o Unicef apresenta seu "plano". Conforme o autor:

Além do baixo custo, o plano sugere o financiamento de espaços educacionais para igrejas de diferentes denominações, dando margem para que se exerça a doutrinação religiosa nos programas das instituições, que muitas vezes têm seus funcionários e diretores escolhidos entre os membros da igreja, exigência ainda hoje presente em alguns regimentos. Para realizar o empreendimento, a utilização das escolas primárias e das municipalidades seria onerosa. Daí, se propõe a convocação das igrejas, 'como entidades de maior difusão nacional, para veículo desse magno empreendimento' (KUHLMANN JR., 2000, p. 489).

Ainda segundo o autor, o Fundo teve o cuidado de realizar um estudo para contabilizar as igrejas existentes em diferentes regiões do País, mas não houve qualquer preocupação com a formação de quem seria responsável pelo trabalho com as crianças. Desse modo: "[...] o pessoal seria recrutado entre 'pessoas de boa vontade', à base de voluntariado, reservandose o pagamento para alguns técnicos necessários à supervisão e coordenação dos serviços, cujos encargos seriam de maior responsabilidade" (KUHLMANN JR., 2000, p. 489).

O que observamos é que, desde a sua origem, ideais como trabalho voluntário e oferta a baixo custo marcam a história das creches, que, se em um primeiro momento se mantêm com trabalho totalmente voluntário, logo demandam contrapartida de recursos por parte do Poder Público. À medida que a demanda aumenta e os movimentos sociais passam a pressionar cada vez mais, os governantes se apropriam de soluções adotadas pelas próprias comunidades, como as mães crecheiras, transformando tais saídas em políticas públicas. 
Estratégias de Privatização da Educação Infantil em Ribeirão Preto e as Resistências

Também o advento das parcerias ou conveniamentos com entidades filantrópicas, religiosas ou comunitárias se generalizam.

Carlos Roberto Jamil Cury, discutindo as relações entre o público e o privado ao longo da história brasileira, menciona um decreto de 1821 e afirma que a falta de recursos está na própria origem da educação brasileira, quando ainda sequer se pensava em qualquer forma de atendimento às crianças pequenas. Conforme Cury, por meio de tal decreto, a Regência do Reino de Portugal permitia "[...] a qualquer cidadão o ensino e a abertura de escolas de primeiras letras" (CURY, 2005, p. 3-4). Ainda conforme o autor, ao tratar da responsabilidade quanto à oferta da educação escolar: "O decreto de 1821 assinala explicitamente dois sujeitos: o Estado e a iniciativa privada". Ao detalhar o conteúdo do referido decreto, todavia, o autor esclarece que desde então a falta de recursos por parte do Estado seria a justificativa - que, digamos, viria a se tornar histórica - para que a iniciativa privada atuasse nesse campo. Um verdadeiro mantra: "O Estado, diz o decreto, é educador e é assim como convém ser. Mas, o erário público, impotente, não aguentaria universalizar esse indispensável estudo das primeiras letras. Daí o repasse parcial dessa responsabilidade para a iniciativa privada" (CURY, 2005, p. 4, grifo no original).

Dando um enorme salto em nossa história educacional, passados 200 anos do decreto mencionado por Cury, como tem sido oferecida a educação infantil em um município do interior do País que se intitula "capital do agronegócio"? Como se encontra a oferta de uma etapa reconhecida apenas com a Constituição Federal de 1988 como direito de toda criança desde o nascimento? Em pleno ano de 2021, após tantas mudanças, entre conquistas e retrocessos, em meio a uma pandemia mundial, o que se pode dizer sobre essa relação entre o público e o privado na oferta de vagas na educação infantil?

\section{Por que o poder público recorre à iniciativa privada para a oferta de educação infantil?}

A histórica precariedade em que se originou e se desenvolveu a educação destinada às crianças pobres de até seis anos, no Brasil, vem sendo evidenciada por diversos trabalhos, com destaque para os de Kuhlmann Jr. (1998). Com a aprovação da Constituição Federal de 1988 (CF/88), um sopro de esperança reverberou entre nós, já que se reconheceu a educação infantil como dever do Estado e como direito de todas as crianças até seis anos de idade (com as mudanças na legislação nacional, atualmente ela recobre a faixa até os cinco anos e 11 meses). A educação infantil também foi reconhecida, com a Lei de Diretrizes e Bases da Educação Nacional, de 1996 (LDB/96), como primeira etapa da educação básica, sujeita, portanto, às normas nacionais que apontavam para o estabelecimento de padrões mínimos de qualidade.

Na sequência desse reconhecimento, todavia, tivemos no Brasil a aprovação de uma política de fundos: o Fundo de Manutenção e Desenvolvimento do Ensino Fundamental e de Valorização do Magistério (Fundef) (BRASIL, 1996), que sugeria uma estagnação na oferta de vagas para essa etapa, em especial para as crianças de zero a três anos, que frequentariam creches. Concluído o prazo de vigência desse fundo, em 2007 foi aprovado o Fundo de Manutenção e Desenvolvimento da Educação Básica e de Valorização dos Profissionais da Educação (Fundeb), que abarcava também a etapa da educação infantil, porém com valores de ponderação que tomavam como base o custo aluno no ensino 
Estratégias de Privatização da Educação Infantil em Ribeirão Preto e as Resistências

fundamental e se mostravam, desde o início, insuficientes para garantir um atendimento de qualidade às crianças dessa faixa etária. Os trabalhos de Carreira e Pinto (2007), Rosemberg (2007), Alves e Pinto (2011) e os de Pinto (2014; 2019), entre outros, são relevantes para o detalhamento desses dois fundos e suas implicações para a ampliação de vagas nos diferentes níveis, etapas e modalidades da educação nacional, além de ressaltarem a distância entre os valores destinados pelo fundo às creches e os seus custos reais.

Para o que nos interessa neste trabalho, destacaremos como os municípios, principais entes responsáveis pela oferta dessa etapa, deram seguimento à tradicional lógica do que alguns autores e autoras vêm chamando de "conveniamento" e as novas formas pelas quais o poder público e instituições privadas vêm estabelecendo suas relações ao longo do tempo (ARELARO, 2008; SUSIN, 2008; BORGHI; ADRIÃO; GARCIA, 2011; COSTA; BORGHI, 2013; OLIVEIRA; BORGHI, 2013; DOMICIANO, 2020).

Como já mencionado, as creches nascem no contexto da filantropia e vão ganhando corpo sob a manutenção dessa lógica, ou seja, de uma suposta ação benevolente, embora cada vez mais contando com financiamento público. É assim que, ao final da década de 1980, Maria Malta Campos (1988) alertava sobre os riscos na relação entre o poder público com o que se conhecia, à época, como Organizações não Governamentais (ONG). Naquele período essa relação era estabelecida com as secretarias de bem-estar social e afins, pois as creches não eram equipamentos que compunham oficialmente as secretarias de educação, o que só veio a acontecer após a LDB de 1996.

Conforme Campos (1988, p. 18), já naquele momento a filantropia era "[...] cada vez mais coberta por recursos originalmente captados através de impostos", ou seja, com recursos públicos, embora de um modo geral o atendimento fosse realizado como um favor. A autora criticava a lógica de uma eficiência supostamente superior em virtude dos menores custos, afirmando que tal lógica não encontraria respaldo na realidade, especialmente no caso da saúde, setor em que esse tipo de serviço era mais disseminado naquele período. Embora levantasse tais questionamentos, ao analisar particularmente o município de São Paulo, a autora observava a relevância dos convênios com o poder público, afirmando que eles representavam, naquele momento, "uma parcela importante do número de vagas oferecidas em creches", e que "[...] as creches mantidas diretamente pela Prefeitura dispunham, no início de 1988, de 22.032 vagas e as creches conveniadas (incluindo-se as chamadas 'indiretas', que funcionavam em prédios construídos e mantidos pela Prefeitura) ofereciam 28.175 vagas" (CAMPOS, 1988, p. 21)

Vê-se, a partir do exemplo da cidade de São Paulo, que também as formas "indiretas" de estabelecimento de convênio já eram correntes, ou seja, o poder público construía o equipamento e o entregava para ser gerido privadamente por ONG, que ainda recebia outros recursos públicos para a sua manutenção. O trabalho de Dalva Franco (2015) é bastante ilustrativo sobre as creches no município de São Paulo e sua histórica relação com entidades privadas sem fins lucrativos.

Os tradicionais arranjos institucionais que viabilizam a oferta de vagas pelo setor privado com financiamento público na educação infantil, todavia, sofreram "atualizações" nas últimas décadas. Oliveira e Borghi (2013) localizaram, dentre os 54 municípios paulistas de grande 
porte $^{1}, 30$, ou seja $55,55 \%$, com conveniamentos para oferta e vagas em creches. Nesse conjunto de municípios, a ampla maioria dos gestores $(80 \%)$ declarou manter convênios com instituições sem fins lucrativos e, dentre estes, uma pequena parcela informou ter parcerias ${ }^{2}$ com instituições privadas com fins lucrativos (OLIVEIRA; BORGHI, 2013).

Jaqueline dos Santos Oliveira (2013) relata que o Programa Bolsa-Creche regulamentado em 2004 pela administração municipal de Limeira foi formalizado por meio de "Termos de Concessão", mesmo instrumento utilizado para concessões de pedagiamento em estradas, por exemplo (OLIVEIRA, 2013). Tal formato possibilitou que "escolas parceiras recebessem recursos públicos e atuassem com objetivo de lucro" (OLIVEIRA, 2013, p. 103).

Observa-se que, ao subsidiar a oferta de vagas para o setor privado, o poder público privatiza a gestão, uma vez que preserva para si exclusivamente o papel fiscalizador sobre as condições infraestruturais da oferta e sobre o processo pedagógico. Cássia Domiciano (2020), em estudo sobre o Programa de Atendimento Especial à Educação Infantil (PAEEI), implementado pela administração municipal de Campinas (SP) no ano de $2007^{3}$, por sua vez, registra ajustes recentes na forma de se estabelecer tradicional convênio por meio de alteração em editais e outros documentos normativos do programa que explicitam como o poder público privatiza a gestão educacional, também na educação infantil, transferindo-a ao setor privado

Segundo a pesquisadora, a alteração no decreto que normaliza o PAEEI, realizada em 2012, insere no documento legal o termo "cogestão" para nomear a relação entre poder público e diferentes instâncias privadas no âmbito do programa. Domiciano observa que o conjunto de responsabilidades sobre a gestão das unidades cabe aos entes privados que as assumem, desde a contratação de pessoal, construção do projeto pedagógico, até a avaliação do trabalho. Cabe ao poder público financiar e fiscalizar. O termo cogestão, portanto, não remete à tradição democrática (DOMICIANO, 2020), mas, com significado oposto, representa a dissimulação da transferência voluntária da gestão educacional a instituições privadas.

Nos limites deste trabalho não é possível explorar os fatores que propiciam a contínua produção de normas que favorecem e estimulam a privatização da educação, sobretudo a partir da reforma gerencial do estado brasileiro nos anos 1990 (GARCIA; ADRIÃO; BORGHI, 2009). Destaca-se, todavia, que se diversificam as formas de privatização nas dimensões do currículo, oferta e gestão educacional (ADRIÃO, 2018; GARCIA, 2018). Verifica-se desde os históricos conveniamentos com instituições filantrópicas e comunitárias até a transferência da oferta e da gestão para instituições privadas com fins lucrativos, e, como ocorre com o PAEEI, com a possibilidade de normativas que explicitam o lugar do sujeito privado na educação pública.

1 Municípios de grande porte têm entre 100.001 e 500.000 mil habitantes, segundo categorização do IBGE (OLIVEIRA; BORGHI, 2013)

2 O termo parceria, recorrente nos documentos de divulgação sobre a atuação do setor privado junto à educação pública, e assim definido na Lei Federal 13.019/2014, é aqui compreendido conforme Adrião (2018), ou seja, como uma forma de privatização, e não como uma relação legítima de colaboração entre dois entes.

3 Segundo Domiciano (2020, p. 2): "As unidades do PAEEI são construídas, equipadas e mantidas pelo poder público, mas têm sua gestão transferida a instituições privadas, selecionadas conforme exigências técnicas e jurídicas publicadas pela prefeitura de Campinas em Edital de processo seletivo público". 
Estratégias de Privatização da Educação Infantil em Ribeirão Preto e as Resistências

\section{Privatização da Educação Infantil: propostas da SME e embates com o Conselho Municipal de Educação}

A cidade de Ribeirão Preto, localizada no interior de São Paulo, com uma população estimada, em 2020, de 712 mil habitantes, já possui um longo histórico de atuação de entidades sem fins lucrativos, em sua maioria confessionais, na educação infantil (JOHANSEN, 2017). A rede municipal de ensino, ao contrário de boa parte dos municípios do interior de São Paulo, também já possui uma longa história, com a presença de escolas já na década de 1960 atendendo ao então ensino primário e à pré-escola. Conforme consta no documento mais atualizado da própria Secretaria Municipal de Educação (SME) de RP (RIBEIRÃO PRETO, 2019b), as pré-escolas têm início por volta dos anos 1950, com os parques infantis. Em 1985 eles recebem a denominação de Escola Municipal de Educação Infantil (EMEI) e somente na década de 1990 as (poucas) creches, vinculadas até então à Secretaria do Bem-Estar Social, passam a integrar a SME. Dados de 1999 indicam o registro de 1.021 crianças em creche e 10.157 na pré-escola (RIBEIRÃO PRETO, 2019b). A fonte indica ainda a presença de 522 matrículas na pré-escola conveniada, para o mesmo ano. No caso das creches, os dados indicam a presença de matrículas conveniadas a partir de 2002, embora seja provável que já houvesse repasses em anos anteriores que não eram contabilizados no Censo Escolar. No ano de 2008, foram identificadas e analisadas, na dissertação de mestrado de Luana Rocha (2015), 15 instituições filantrópicas e quatro comunitárias cadastradas no FNDE, totalizando 697 matrículas em creche. O mesmo trabalho identificou, em 2013, último ano analisado pela pesquisadora, 14 instituições filantrópicas e quatro comunitárias.

Por outro lado, desde a gestão de Dárcy Vera (2008-2016) o Ministério Público (MP), no âmbito de um inquérito civil, vinha buscando a concretização de um Termo de Ajustamento de Conduta (TAC) com a administração municipal de Ribeirão Preto, com vistas a uma solução estrutural para a demanda não atendida, em especial nas creches. No âmbito dessa gestão, que terminou com a prisão da então prefeita, acusada de corrupção, chegou-se a um esboço de proposta ao final de 2015 , segundo a qual a administração municipal se comprometia a construir 17 creches, zerando o déficit estimado de 2.483 vagas na educação infantil, além de se comprometer com a progressiva extinção dos convênios (RIBEIRÃO PRETO, 2017). Com a eleição de Antônio Duarte Nogueira Júnior, em 2016, as tratativas passaram a caminhar de forma mais lenta, em função, entre outras coisas, da grande rotatividade das titulares da SME; foram três no primeiro mandato. Não é à toa que, de 2016 a 2019, as matrículas da rede municipal praticamente ficaram estagnadas, não obstante a promessa de campanha de Duarte Nogueira de construir 15 novas creches (DUARTE..., 2016).

Dando sequência a esse movimento, encontramos na análise de Raquel Purificação (2017) dados referentes ao recém-criado e denominado Cadastro Geral Unificado (CGU), implantado em 2016 pela SME para centralizar os pedidos por matrículas realizados pelas famílias e, em certa medida, dar alguma publicidade e possibilidade de controle à histórica lista de espera no município. Conforme os dados do CGU apresentados por Purificação (2017), naquele ano já se somavam 3.683 crianças aguardando por uma vaga em creche, sendo a maior concentração de pedidos na faixa do berçário I e II, bebês com até 12 e 24 meses, respectivamente. 
Estratégias de Privatização da Educação Infantil em Ribeirão Preto e as Resistências

$\mathrm{Na}$ dissertação de Danieli Rocha Chiuzuli (2020), que analisa o processo de judicialização pelo direito à creche, encontramos dados sobre a criação do I Fórum de Educação Infantil. Conforme a autora,

[...] o PAA (Procedimento Administrativo de Acompanhamento) foi instaurado em 29 de março de 2016, em decorrência da representação de autoria da Associação dos Profissionais do Ensino de Ribeirão Preto (APROFERP) sobre a situação das creches em Ribeirão Preto. No âmbito desse procedimento, foi instaurado o I Fórum de Educação Infantil que teve sua primeira audiência pública em 10 de junho de 2016 (CHIUZULI, 2020, p. 157).

Destacado esse processo de embates e tentativas de saídas socialmente construídas para que o direito à creche fosse devidamente garantido, passamos a apresentar os dados quantitativos sobre a evolução na oferta de vagas em educação infantil no município. Neste artigo, consideraremos o período entre 2008 e 2019, quando os dados estão melhor contabilizados no âmbito do Laboratório de Dados Educacionais (LDE) da Universidade Federal do Paraná (UFPR), que sistematiza informações do Censo Escolar do INEP e servirá de base para os indicadores apresentados a seguir.

O Gráfico 1, a seguir, apresenta a evolução das matrículas em creche no município para o período de 2008 a 2019 por dependência administrativa.

Gráfico 1 - Ribeirão Preto: evolução das matrículas em creches por dependência administrativa 2008-2019

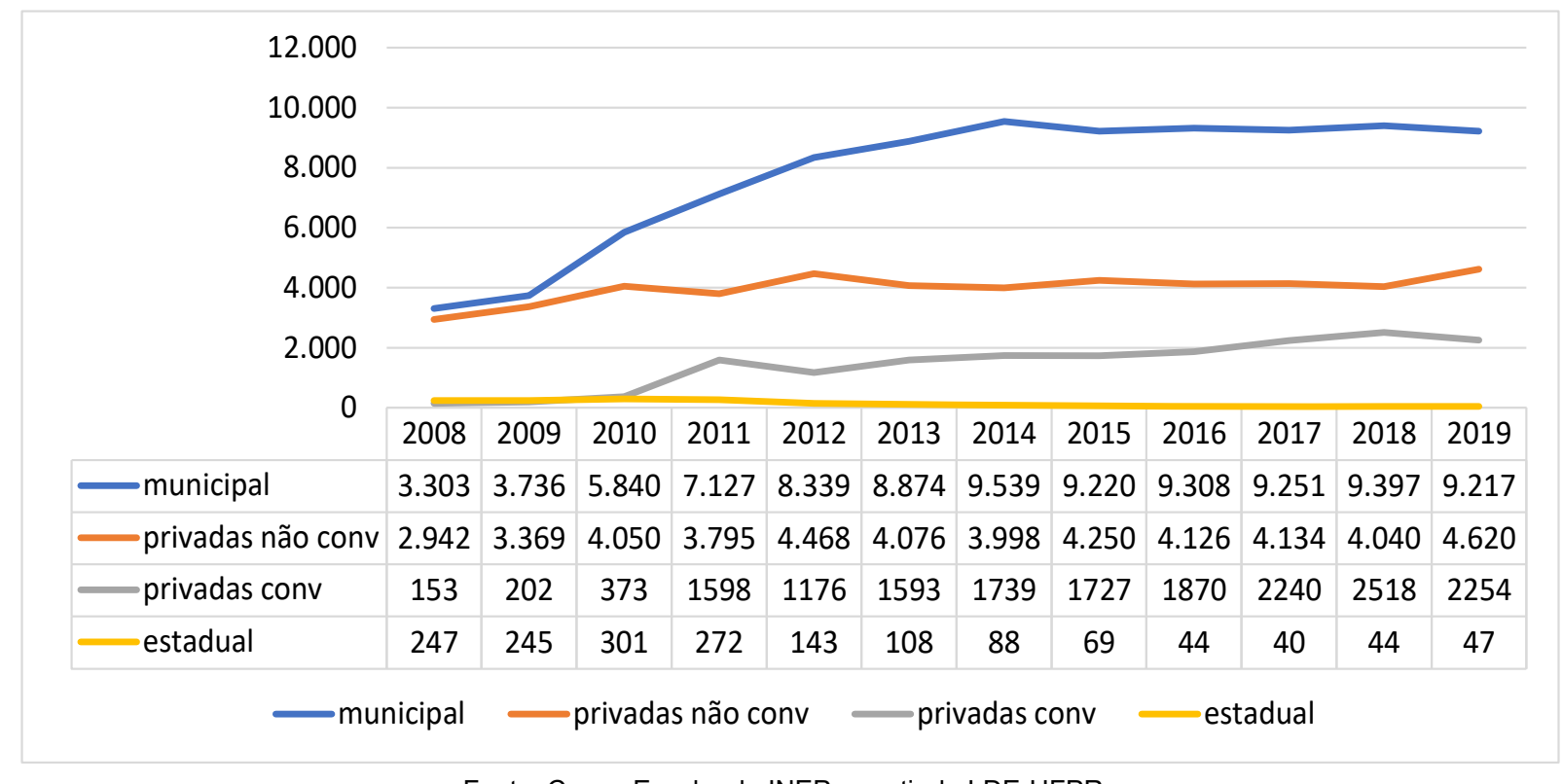

Fonte: Censo Escolar do INEP a partir do LDE-UFPR.

Os dados do Gráfico 1 indicam a grande expansão da rede municipal, em especial até 2014, quando as matrículas praticamente se estabilizam. Entre 2008 e 2014 o crescimento foi de $189 \%$. A rede privada não conveniada apresentou também crescimento no período, em particular entre 2008 e 2010 (38\%), quando tende à estabilização, voltando a apresentar uma expansão no último ano da série. Já a rede conveniada parte de um patamar bem baixo de matrículas e mostra uma ampliação constante em toda a série histórica. Entre 2008 e 2013 ela cresce $941 \%$ e a partir daí cresce em taxas menores, com uma queda no último ano. É importante ressaltar que oscilações nos dados podem decorrer de problemas em seu 
Estratégias de Privatização da Educação Infantil em Ribeirão Preto e as Resistências

preenchimento, por isso a importância da análise da série histórica. Do ponto de vista da participação no total de matrículas, a rede municipal saiu de um índice de 50\%, atingindo um patamar máximo de $62 \%$, em 2014 , fechando a série com $57 \%$. Já a presença da rede privada não conveniada caiu de $44 \%$ do total, em 2008, para $29 \%$, em 2019 , atingindo o menor valor em 2018 (25\%). Quanto à rede conveniada, essa participação saltou de 2\%, em 2008, para 14\%, em 2019, com um ápice em 2018 (16\%). Por fim, a rede estadual, representada essencialmente por uma creche no campus da Universidade de São Paulo (USP) e outra no Hospital de Clínicas (HC), teve uma presença insignificante, e pior, decrescente no período.

O Gráfico 2 apresenta, agora, de maneira análoga, a evolução das matrículas da préescola.

\section{Gráfico 2 - Ribeirão Preto: evolução das matrículas em pré-escolas por dependência} administrativa

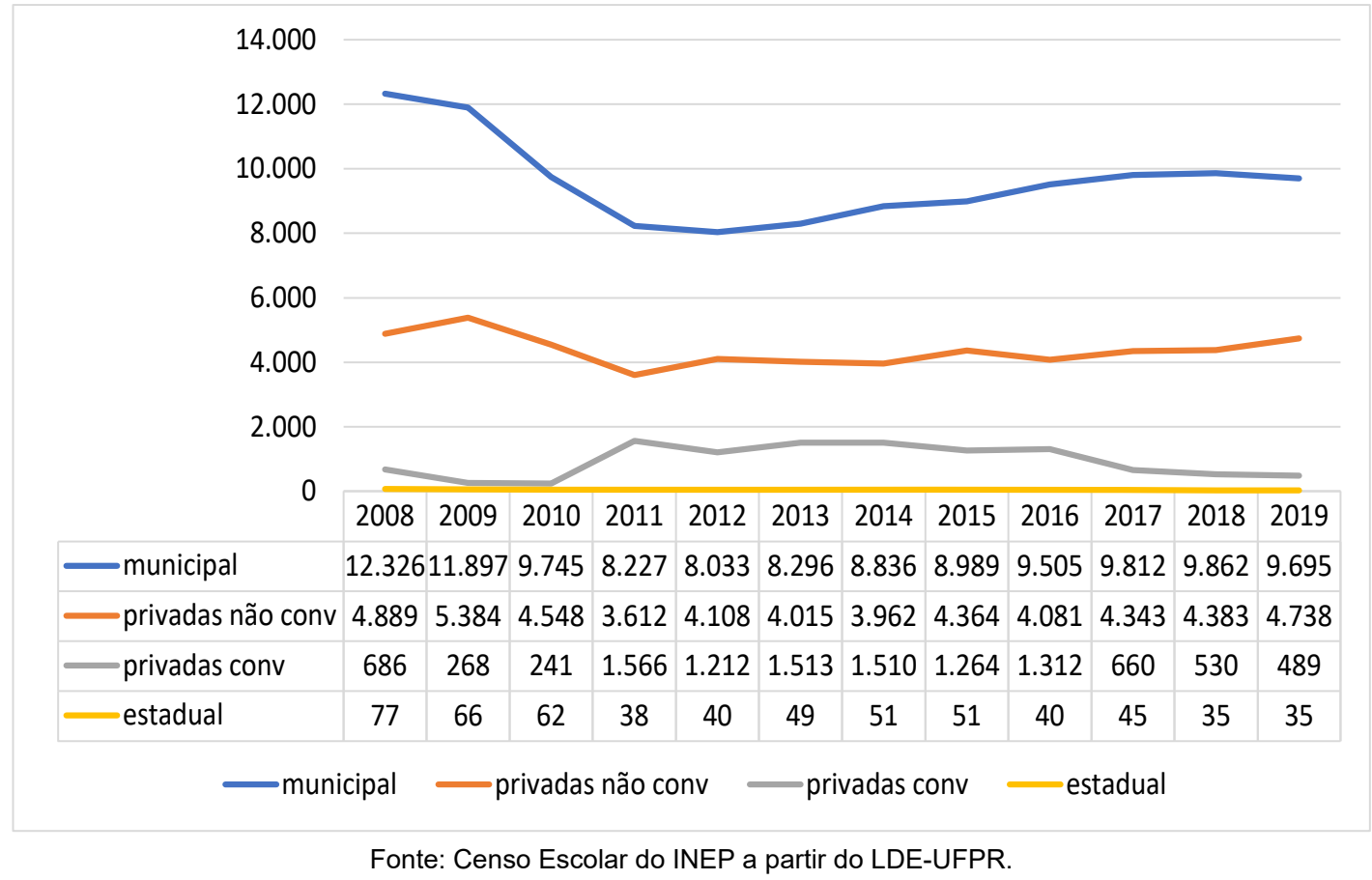

Para que se entenda a dinâmica do Gráfico 2 é importante lembrar a aprovação da Lei 11.274 (BRASIL, 2006), que ampliou a duração do ensino fundamental de oito para nove anos, incorporando a faixa etária de seis anos, o que, por consequência, reduziu a pré-escola apenas para duas coortes etárias (quatro e cinco anos). Essa lei, aprovada em 2006, fixou um prazo de transição até 2010. Esse fato pode explicar a grande queda de matrículas na rede municipal e privada não conveniada até 2011, quando se inicia um novo ciclo de crescimento, associado às crianças na faixa etária que passaram a ingressar nas redes de ensino. Já a rede privada conveniada apresentou uma queda consistente, atingindo, em 2019, apenas $31 \%$ de suas matrículas em 2011. Tal queda está relacionada a discussões ocorridas no âmbito do Conselho Municipal de Educação (CME), que passou a questionar o grande número de matrículas conveniadas na pré-escola quando a grande demanda reprimida do município estava nas creches ${ }^{4}$. De 2012 a 2016 a rede privada não conveniada ficou praticamente

4 Como um dos autores do trabalho foi membro do CME por todo esse período, foram incluídas informações dessa vivência, mas que constam nas atas do Conselho. 
Estratégias de Privatização da Educação Infantil em Ribeirão Preto e as Resistências

estabilizada, com um leve crescimento no final da série. Já a rede municipal apresentou um crescimento de $20 \%$ entre 2011 e 2018 , com uma pequena queda em 2019 . Do ponto de vista da participação no total de matrículas, a rede municipal variou de $69 \%$, em 2008 , para $65 \%$, em 2019, enquanto a rede privada não conveniada, no mesmo período, foi de $27 \%$ para $32 \%$. Já a rede privada conveniada saiu de um patamar de 4\%, em 2008, atingindo 11\% em 2013, seu maior valor, para cair para $3 \%$, em 2019 , pelos motivos já alegados.

Quando se analisa a evolução da soma de matrículas em creches e pré-escolas no período de 2011 a 2019 na rede privada conveniada, observa-se uma relativa estabilidade em torno de 3 mil matrículas, indicando que a queda na pré-escola foi compensada pelo crescimento no atendimento em creche. $\mathrm{Na}$ análise das instituições que realizaram convênio com a prefeitura neste período, percebe-se que 17 delas se mantiveram constantes, com pequenas oscilações nas matrículas. Em sua maioria eram instituições de cunho confessional e filantrópico e de pequeno porte: das 17, nove atendiam até 100 crianças; seis, entre 101 e 200, e apenas duas instituições atendiam entre 201 e 300 crianças. Segundo dados do CME e aqueles sistematizados por Purificação (2020), em boa parte desse período, pelo menos até a eleição de Duarte Nogueira, em 2016, os valores eram repassados mensalmente, sem diferenciação entre as instituições, em valores inferiores ao estimado por aluno do Fundeb para o estado de São Paulo. O CME também regulou o uso dos recursos, após a constatação de seu uso para atividades não diretamente relacionadas à educação, como, entre outras coisas, o pagamento do licenciamento anual de veículos das instituições.

Ante a pressão pelo atendimento da demanda reprimida, tanto por parte do MP quanto do CME e de outras instituições da sociedade civil, a SME optou por um caminho similar ao adotado por São Paulo e Campinas, buscando expansão através da intensificação de parcerias com o setor privado. O elemento simbólico da mudança foi a obtenção, pelo município, de um prédio destinado à educação infantil com capacidade para 1.036 alunos entre creche e pré-escola, como contrapartida de uma construtora que criou um empreendimento popular com cerca de 7 mil moradias, em região anexa ao anel viário da cidade e sem qualquer equipamento social. Inicialmente a SME buscou aprovar a parceria no âmbito do CME, que se posicionou contrariamente, pois envolvia a cessão de um prédio, além da garantia, pelo município, da oferta de alimentação escolar, entendendo o Conselho que o mais adequado seria que o próprio município assumisse o equipamento, até porque existiam professores aprovados no último concurso e não convocados. Ante a posição do $\mathrm{CME}$, o Executivo enviou um projeto de lei à Câmara de Vereadores, que foi aprovado (Lei no 14.370 de 26/07/2019) (RIBEIRÃO PRETO, 2019a). A nova lei dispunha sobre a qualificação de entidades sem fins lucrativos para atuarem na Educação Infantil com vistas a atuar em parceria com a administração pública e exigia experiência prévia comprovada de atuação na educação infantil de, pelo menos, cinco anos. Além disso, listava a disponibilidade de sete equipamentos municipais para as assim chamadas parcerias. Com base na lei, a prefeitura abriu dois editais de chamamento público de interessados (RIBEIRÃO PRETO, 2021), com a disponibilização de três equipamentos, o prédio já citado, com 1.036 vagas em potencial e mais dois outros, com 94 vagas cada. Contudo, não apareceram interessados. Nos dois primeiros editais a grande justificativa era a fila de espera na faixa de 0 a 3 anos, e alegavase que a faixa da pré-escola já estava universalizada no município. Então, lançou-se um terceiro edital no qual não se remete mais à lei municipal, mas apenas à Lei federal $13.019 / 2014$, muito mais permissiva, e rebaixa-se a exigência de experiência para apenas 
Estratégias de Privatização da Educação Infantil em Ribeirão Preto e as Resistências

três anos. Nos três editais, o valor por criança era de $\mathrm{R} \$ 572$ na creche em tempo integral e $\mathrm{R} \$ 269,71$ na pré-escola parcial. Somente uma instituição local (com mais tradição na assistência social e experiência apenas em pré-escola e com poucas matrículas) mostrou interesse e foi aprovada para assumir o equipamento no novo bairro criado.

Aqui cabe um destaque, pois nesse equipamento foram abertas mais vagas na préescola (600) do que na etapa de creches (436), embora o próprio edital declarasse a universalização da faixa de 4 e 5 anos. Em relação aos outros dois equipamentos, como não apareceram interessados, e ante a pressão da demanda, a SME acabou assumindo a gestão, atendendo apenas à faixa de 0 a 3 anos com uma capacidade total de 198 crianças.

Finalmente, em dezembro de 2020, a SME muda novamente as regras: não declara mais a universalização da faixa etária da pré-escola, reduz a experiência exigida na área para apenas um ano e realiza novo chamamento público para estabelecer parcerias por meio de "termos de colaboração mútua" com Organizações da Sociedade Civil (OSC) sem fins lucrativos. O intuito declarado foi o de oferecer vagas na educação infantil, incluindo agora nove unidades pertencentes ao município e oriundas da conclusão de obras iniciadas na gestão Darcy Vera e de transferências do SESI (RIBEIRÃO PRETO, 2020), que fechou unidades no município. A Tabela 1 apresenta os limites (máximos) de vagas em cada equipamento e o valor por criança matriculada a ser repassado mensalmente às instituições selecionadas.

Tabela 1 - Ribeirão Preto: vagas disponibilizadas e valor por matrícula por equipamento - 2020

\begin{tabular}{|c|c|c|c|c|}
\hline \multirow{2}{*}{ Unidade } & \multicolumn{2}{|c|}{ Creches } & \multicolumn{2}{c|}{ Pré-escola } \\
\cline { 2 - 5 } & vagas & valor & vagas & valor \\
\hline 1 & 220 & 620 & 200 & 300 \\
\hline 2 & 216 & 740 & 200 & 300 \\
\hline 3 & 206 & 770 & 200 & 300 \\
\hline 4 & 129 & 1060 & 0 & - \\
\hline 5 & 135 & 790 & 184 & 320 \\
\hline 6 & 135 & 790 & 184 & 320 \\
\hline 7 & 135 & 790 & 184 & 320 \\
\hline 8 & 135 & 790 & 184 & 320 \\
\hline 9 & 135 & 790 & 184 & 320 \\
\hline Total & 1446 & - & 1520 & - \\
\hline
\end{tabular}

Fonte: Elaboração dos autores com base em dados de Ribeirão Preto (2020).

Pode-se dizer que esse edital representou uma guinada em relação à política de parcerias com o setor privado adotada nas últimas décadas no município, pois apresentou as seguintes alterações: 
Estratégias de Privatização da Educação Infantil em Ribeirão Preto e as Resistências

- Cessão de prédios públicos e oferta de alimentação;

- Quantidade de vagas disponibilizadas, superior ao dobro do total de 2019;

- Priorização da pré-escola, que não apresenta demanda reprimida, com objetivo aparente de tornar o chamamento mais atrativo para as instituições privadas, pois os custos são bem menores: as vagas no edital correspondem a 3,1 vezes a matrícula conveniada na pré-escola, em 2019;

- Valores diferenciados por equipamento, sem qualquer planilha de custo que os justifique no edital, e em contradição com a economia de escala, pois o valor por estudante indicado é maior em instituições maiores, quando os custos per capita variam inversamente com o tamanho.

$\mathrm{Na}$ primeira publicação do edital (com uma errata) apenas duas instituições se apresentaram: uma, local, de caráter confessional e com larga experiência na área, pleiteando um equipamento e, uma segunda, de Presidente Prudente/SP, pleiteando todos os demais equipamentos. A comissão de avaliação da SME habilitou e aprovou as duas instituições. $O$ processo foi encaminhado, então, ao CME. Em sua análise o CME deu parecer favorável à instituição local e negativo àquela de Presidente Prudente, argumentando que a instituição, embora tivesse sede naquele município, apresentava como endereço um local pertencente a um escritório de contabilidade, seus diretores residiam em São Paulo e sua única experiência, inferior a um ano, havia sido a gestão de uma creche em Campinas, portanto, descumpria o edital. A SME, inicialmente, contestou o parecer do CME, mas, por fim, tornou nulo o efeito do edital, em 10 de fevereiro de 2021 (RIBEIRÃO PRETO, 2021a). Então, com a justificativa da urgência para a garantia de vagas, a SME renunciou ao instrumento de Edital de Chamamento e, também com base na Lei 13.019 de 2014, encaminhou convites a um conjunto de entidades do próprio município com as quais já havia algum tipo de colaboração (RIBEIRÃO PRETO, 2021b).

Até o momento da conclusão deste artigo, o CME foi instado a elaborar um parecer sobre três dessas unidades, que, segundo a SME, estariam em condições de iniciar o atendimento. Nossa análise, portanto, será sobre os principais aspectos levantados no relatório elaborado pela comissão nomeada pelo CME (CME, 24/03/2021) em relação às propostas apresentadas por essas três entidades e que foi aprovado pelo plenário. São elas: Unificação Kardecista de Ribeirão Preto, Liga das Senhoras Católicas e Casa de Emanuel. O Quadro 1, a seguir, apresenta as vagas e os valores envolvidos nas três unidades, assim como o total de matrículas e os valores que serão praticados para as unidades que já possuem convênio com a prefeitura, anteriores ao atual formato. 
Estratégias de Privatização da Educação Infantil em Ribeirão Preto e as Resistências

Quadro 1 - Edital 2020: entidades, Unidades de Educação Infantil (UEI), vagas, valores e formalização da parceria

\begin{tabular}{|l|l|c|c|c|c|l|}
\hline \multirow{2}{*}{ ENTIDADE } & \multicolumn{1}{|c|}{ UEI } & \multicolumn{2}{|c|}{ Creches } & \multicolumn{2}{c|}{ Pré-escolas } & Formalização da \\
\cline { 2 - 6 } & & Vagas & $\begin{array}{c}\text { Per } \\
\text { capita/mês }\end{array}$ & Vagas & $\begin{array}{c}\text { Per } \\
\text { capita/mês }\end{array}$ & \\
\hline $\begin{array}{l}\text { Unificação } \\
\text { Kardecista de } \\
\text { Ribeirão Preto }\end{array}$ & $\begin{array}{l}\text { Parque dos } \\
\text { Pinus }\end{array}$ & 129 & 1060 & - & - & $\begin{array}{l}\text { Convite - } \\
\text { Termo de colaboração }\end{array}$ \\
\hline $\begin{array}{l}\text { Liga das } \\
\text { Senhoras } \\
\text { Católicas de RP }\end{array}$ & Ipiranga & 206 & 770 & 200 & 300 & $\begin{array}{l}\text { Convite - } \\
\text { Termo de colaboração }\end{array}$ \\
\hline $\begin{array}{l}\text { Casa de } \\
\text { Emanuel }\end{array}$ & V. Virgínia & 220 & 620 & 200 & 300 & $\begin{array}{l}\text { Convite - } \\
\text { Termo de colaboração }\end{array}$ \\
\hline $\begin{array}{l}\text { Demais } \\
\text { instituições em } \\
2021\end{array}$ & 21 unidades & $2.887^{*}$ & 595 & $709^{*}$ & 280,50 & Convênio/parceria \\
\hline
\end{tabular}

Obs.: * Matrículas efetivas.

Fonte: Edital 1/2020 e Ofício SME 240/2021.

Os dados do Quadro 1 mostram inicialmente a já citada ausência de coerência entre elementos de variação do valor per capita dos repasses mensais (12 parcelas) e parâmetros de custos. Um segundo aspecto, salientado no relatório aprovado pelo CME (CME, 24/03/2021) (RIBEIRÃO PRETO, 2021c), é a discrepância entre os valores que serão repassados por aluno às instituições que pretendem assumir as três unidades e aqueles repassados para as 21 unidades (três delas administradas por essas mesmas instituições) que já possuíam convênio com a prefeitura. Nos novos termos de colaboração, além de variáveis para cada unidade de ensino, os valores chegam a ser $78 \%$ superiores (no caso da Creche dos Pinus) entre os novos contratos e aqueles já existentes. Conforme alerta o relatório apresentado ao $\mathrm{CME}$, por se tratar de mero convite, sem qualquer elemento concorrencial, e ante a ausência de planilhas de custo no termo de referência do Convite que justifiquem as diferenças, essas disparidades fatalmente ensejarão questionamentos jurídicos quanto à falta de isonomia nos repasses, considerando que os serviços a serem prestados são equivalentes.

Ao debruçar-nos nas planilhas de custo apresentadas pelas entidades, o relatório apresentado ao CME indica várias incongruências, que resumimos a seguir:

- enorme aumento nas despesas administrativas envolvendo aumento de pessoal e de remuneração. Por exemplo, a entidade Liga das Senhoras Católicas, que já administra uma unidade que atende cerca de 300 crianças entre creche e pré-escola com dois diretores com contrato de $40 \mathrm{~h}$ e remuneração mensal de $\mathrm{R} \$ 5.250$, em sua proposta para a unidade do Ipiranga (limite de 406 matrículas) apresenta as seguintes "inovações": uma demanda de três diretores, cada qual com uma jornada de $20 \mathrm{~h}$ de trabalho semanais, mas, pelo mesmo valor salarial de $\mathrm{R} \$ 5.250$. Ou seja, o salário dos gestores (que em parte são os mesmos que já atuam na outra unidade conveniada) simplesmente dobra de valor, enquanto os professores ganharão apenas o piso previsto na convenção coletiva da rede privada, a saber, $\mathrm{R} \$ 2.970$ por $44 \mathrm{~h}$ de trabalho semanal (jornada dupla, mas sem hora-extra) e sem previsão de horaatividade, apenas um adicional de $5 \%$ a este título. Já a Unificação Kardecista, que atualmente já possui uma creche conveniada com cerca de 80 crianças (a $R \$ 595 /$ mês, em 2021), segundo a SME, mas com 180 crianças, segundo o Censo Escolar, declara administrar o atual equipamento com apenas um coordenador pedagógico e um diretor (voluntário); na proposta 
Estratégias de Privatização da Educação Infantil em Ribeirão Preto e as Resistências

para a Creche dos Pinus (129 vagas a $\mathrm{R} \$ 1.060$ por criança) surge a demanda por um diretor pedagógico ( $R$ \$ 6.300), um coordenador pedagógico ( $R$ \$ 3.200), um coordenador administrativo ( $R \$ 3.200)$ e um assistente de diretor administrativo ( $R \$ 3.000)$, além de um funcionário administrativo ( $R \$ 1.750)$;

- uma das hipóteses plausíveis é a de que os custos com pessoal administrativo estejam ocultando despesas administrativas da instituição proponente, o que é vedado. O mais grave é que o Termo de Referência (TR) estabelece que "Os valores a serem percebidos pela equipe gestora (Diretor, vice-diretor e coordenador pedagógico) da Escola deverá ser igual ao piso estabelecido na Convenção Coletiva de Trabalho dos Auxiliares de Administração Escolar do Ensino Básico, do SINPAE (Sindicato dos Professores e Auxiliares de Administração Escolar) de Ribeirão Preto e Região"; ocorre que, na convenção, não é definido um piso para a equipe gestora, o que levou o CME a declarar a nulidade do TR conforme sugere o relatório da comissão (CME, 24/03/21). Curiosamente, nas planilhas das entidades a previsão de remuneração dos docentes encontra-se muito abaixo da remuneração da rede municipal de ensino; enquanto a dos gestores é bem superior, em valor e quantidade de profissionais por unidade;

- após instado pelo CME, a SME apresentou as planilhas que, segundo ela, embasaram os valores expressos no TR. Elas não justificam, contudo, várias das despesas estimadas, com incongruências nas previsões de encargos trabalhistas e em outras despesas de custeio e capital. Curiosamente, mesmo apresentando lista de insumos muito distintos, as planilhas das entidades proponentes coincidem com os valores finais das planilhas da SME. Destaque-se que a planilha da Unificação Kardecista apresenta a previsão de férias como encargo, o que não se justifica, uma vez que são feitos 12 repasses anuais, sendo encargo apenas o adicional de um terço de férias. Há a previsão também de um professor de artes ( $R \$ 3.000)$, um de música $(R \$ 3.000)$ e um psicólogo $(R \$ 1.000)$, quando nenhum desses itens consta na planilha da prefeitura, e, considerando se tratar de atendimento à faixa de 0 a 3 anos, parecem questionáveis. Na proposta da Liga das Senhoras Católicas consta também a previsão de um psicólogo e, nos dois casos, a alegação é uma exigência legal (BRASIL: Lei n 13.935/19). Contudo, essa lei se refere apenas a redes públicas de ensino e não determina a presença dos psicólogos nas escolas;

- finalmente, o relatório aprovado pelo CME chama atenção para o fato de que, em reunião com a equipe da SME, os membros da comissão haviam alertado para a presença de uma relação de parentesco entre a dirigente da entidade Unificação Kardecista e um vereador do município (que havia sido seu presidente até 2020), que foi informado que a entidade havia se ajustado à vedação legal, embora fosse de notório conhecimento o vínculo da entidade que passaria a administrar dois equipamentos com recebimento de recursos públicos com a família do edil.

Além dos aspectos levantados no relatório aprovado pelo CME, gostaríamos de ressaltar mais alguns:

- com relação à Casa de Emanuel, observamos a utilização de uma linguagem inadequada na apresentação de seu plano de trabalho: para se referir à criança, utilizaram o termo "menor"; para se referir ao que seria parte do trabalho pedagógico com as crianças, afirmaram: "Prover meios para a recuperação dos alunos de menor rendimento" (p. 11). Além disso, foi constatado o uso de uma oração religiosa com o objetivo de traduzir em linguagem mais 
Estratégias de Privatização da Educação Infantil em Ribeirão Preto e as Resistências

simples uma citação de Edgar Morin (p. 46). Ora, o "código do menor" foi extinto e a criança passou a ser compreendida como sujeito de direitos desde a Constituição Federal de 1988. "Recuperação" e "rendimento" não são expressões próprias à Educação Infantil, etapa cujo trabalho pedagógico deve ser caracterizado pelas interações e brincadeiras. Finalmente, a educação pública, ainda que gerida por uma OSC, e ainda que esta seja confessional, na medida em que está sendo financiada e mantida com recursos públicos, deve garantir seu caráter laico, respeitando-se, assim, a diversidade cultural e religiosa de todos que a frequentam;

- também chama atenção a diferença salarial para os mesmos cargos entre as diferentes instituições, como é o caso dos professores. Ademais, para as designações diferenciadas que foram encontradas nos planos de trabalho, tais como "professor habilitado", "professor habilitado de apoio" ou "professor I e professor II", embora haja a carga horária e o salário, não há especificação sobre a formação mínima exigida, se ensino médio na modalidade "normal" ou se ensino superior, com Pedagogia. Destacamos também que, embora haja menção à formação continuada nos diferentes planos, considerando a quantidade e a carga horária dos professores, bem como de auxiliares, não vislumbramos a possibilidade de que haja tempo durante a jornada diária para tal formação, já que na maioria dos casos o atendimento às crianças em creches se dará em período integral.

Aliás, essa é outra questão a considerar: no caso das etapas (4 e 5 anos), em atendimento de meio período, cada professora assumirá uma turma em cada turno? E no caso das crianças de 0 a 3 anos, cada professora assumirá uma turma por oito horas diárias? Quem ficará com as crianças durante o horário de almoço, por exemplo? Embora não tenhamos resposta oficial a tais perguntas, o que os estudos sugerem é que esse modelo de contratação significa jornadas de trabalho extenuantes, rebaixando-se, assim, a própria qualidade do trabalho com as crianças (FRANCO, 1989; CORREA, 2018; FRANCO; DOMICIANO; ADRIÃO, 2019). A qualidade envolve condições materiais diversas, mas, sobretudo, diz respeito às condições de trabalho das professoras e professores. Trabalhar em jornada integral com crianças pequenas, sem a previsão de carga horária para formação continuada, sem planos de carreira e com salário inferior aos percebidos por colegas que atuam na rede pública municipal são alguns dos principais elementos que evidenciam um aprofundamento das desigualdades, já tão marcantes em nossa sociedade. Além disso, o trabalho nessas condições pode levar ao absenteísmo e até ao abandono da profissão, provocando, assim, uma alta rotatividade entre os profissionais que são os principais responsáveis por uma educação de qualidade aos pequenos.

Deve-se registrar que, embora o edital e na sequência o comunicado/convite sejam dirigidos a Organizações da Sociedade Civil, entidades, portanto, sem fins lucrativos imediatos, não há nos documentos nenhuma restrição a que estas organizações transfiram o recurso público para instituições com fins lucrativos, a exemplo das que oferecem produtos voltados às atividades fins como sistemas privados de ensino. A transferência da gestão para esses entes privados tem, assim, potencial para levar recursos públicos à realização do lucro. Considerando-se o já indicado atendimento à pré-escola e o crescente mercado destinado a esta etapa da educação básica, essa é uma possibilidade real. 
Estratégias de Privatização da Educação Infantil em Ribeirão Preto e as Resistências

\section{Considerações finais}

A educação infantil no Brasil tem uma longa história de baixo atendimento, subfinanciamento e ausência estatal. Com a CF de 1988 e suas alterações, assim como com os Planos Nacionais de Educação, esse quadro vinha dando sinais de alteração, com a ampliação do atendimento e das matrículas públicas em creches e pré-escolas. Contudo, com as aberturas deixadas no âmbito do Fundeb, e mesmo da CF, de destinação de recursos públicos para o setor privado de ensino, sob a mitologia do 'Estado ineficiente' e das 'maravilhas do mercado', com as pressões da demanda na faixa de 0 a 5 anos, com a sobrecarga financeira dos municípios em contexto de estagnação econômica, o velho estigma da substituição da ação do Estado pelo setor privado 'não lucrativo', e não apenas este, para reduzir custos, que marcou desde o início a história da educação infantil, parece estar de volta, em especial nos municípios de grande porte. No caso do município analisado há um agravante, pois Ribeirão Preto possui os prédios (alguns abandonados pelo Sesi, que reduziu sua oferta no Ensino Fundamental) e receita de impostos suficiente para assumir a expansão do atendimento, mas houve uma clara opção ideológica pela via da privatização desses equipamentos, à custa dos direitos das crianças, que já poderiam estar frequentando escolas municipais há mais de um ano. Nesse sentido, a estratégia adotada pela SME de Ribeirão Preto é mais um exemplo da crescente privatização da gestão educacional do País.

\section{Referências}

ADRIÃO, T. Dimensões e Formas da Privatização da Educação no Brasil: caracterização a partir de mapeamento de produções nacionais e internacionais. Currículo sem Fronteiras, v. 18, p. 8-28, 2018.

ALVES, T.; PINTO, J. M. R Remuneração e características do trabalho docente no brasil: um aporte. Cadernos de Pesquisa, Campinas, v. 41 n. 143, p. 606-639, maio/ago. 2011. Disponível em: https://www.scielo.br/pdf/cp/v41n143/a14v41n143.pdf. Acesso em: 28 mar. 2021.

ARELARO, L. A não-transparência nas relações público-privadas: o caso das creches conveniadas. In: ADRIÃO, T.; PERONI, V. Público e privado na educação: novos elementos para o debate. São Paulo: Xamã, 2008. p. 51-66.

BORGHI, R.; ADRIÃO, T.; GARCIA, T. As parcerias público-privadas para a oferta de vagas na educação infantil: um estudo em municípios paulistas. Revista Brasileira de Estudos Pedagógicos, v. 231, p. 124-138, 2011. Disponível em: http://rbep.inep.gov.br/ojs3/index.php /rbep/article/view/3621. Acesso em: 20 mar. 2021.

BRASIL. Constituição da República Federativa do Brasil. Diário Oficial da União, Brasília, 1988. Disponível em: http://www.planalto.gov.br/ccivil_03/constituicao/constituicao.htm Acesso em: 03 mar. 2021.

BRASIL. Lei $n^{\circ}$ 9.394, de 20 de dezembro de 1996. Estabelece as diretrizes e bases da Educação Nacional. Diário Oficial da União, Brasília, 1996a. Disponível em: http://www.planalto.gov.br/ccivil_03/leis/19394.htm. Acesso em: 30 jul. 2021. 
Estratégias de Privatização da Educação Infantil em Ribeirão Preto e as Resistências

BRASIL. Lei $n^{\circ}$ 9.424, de 24 de dezembro de 1996. Dispõe sobre o Fundo de Manutenção e Desenvolvimento do Ensino Fundamental e de Valorização do Magistério, na forma prevista no art. $60, \S 7^{\circ}$, do Ato das Disposições Constitucionais Transitórias, e dá outras providências. Diário Oficial da União, Brasília, 1996b. Disponível em: http://www.planalto.gov.br/ccivil_ 03/LEIS/L9424.htm. Acesso em: 5 maio 2021.

BRASIL. Lei $n^{\circ}$. 11.274, de 6 de fevereiro de 2006. Altera a redação dos artigos 29, 30, 32 e 87 da Lei $n^{\circ}$ 9.394, de 20 de dezembro de 1996, que estabelece as diretrizes e bases da educação nacional, dispondo sobre a duração de 9 (nove) anos para o ensino fundamental, com matrícula obrigatória a partir dos 6 (seis) anos de idade. Diário Oficial da União, Brasília, 2006. Disponível em: http://www.planalto.gov.br/ccivil_03/_ato2004-2006/2006/lei/l1 1274.htm. Acesso em 20 fev. 2021.

BRASIL. Lei n. 11.494, de 20 de junho de 2007. Regulamenta o Fundo de Manutenção e Desenvolvimento da Educação Básica e de Valorização dos Profissionais da Educação FUNDEB, de que trata o art. 60 do Ato das Disposições Constitucionais Transitórias; altera a Lei $\mathrm{n} \times 10.195$, de 14 de fevereiro de 2001; revoga dispositivos das Leis $\mathrm{n}^{\circ \mathrm{s}} 9.424$, de 24 de dezembro de 1996, 10.880, de 9 de junho de 2004, e 10.845, de 5 de março de 2004; e dá outras providências. Diário Oficial da União, Brasília, 2007. Disponível em: http://www. planalto.gov.br/ccivil_03/_ato2007-2010/2007/lei//11494.htm. Acesso em: 30 jul. 2021.

BRASIL. Lei $n^{\circ} 13.019$, de 31 de julho de 2014. Estabelece o regime jurídico das parcerias entre a administração pública e as organizações da sociedade civil, em regime de mútua cooperação, para a consecução de finalidades de interesse público e recíproco, mediante a execução de atividades ou de projetos previamente estabelecidos em planos de trabalho inseridos em termos de colaboração, em termos de fomento ou em acordos de cooperação; define diretrizes para a política de fomento, de colaboração e de cooperação com organizações da sociedade civil; e altera as Leis $n^{\circ} 8.429$, de 2 de junho de 1992, e 9.790, de 23 de março de 1999. (Redação dada pela Lei $n^{\circ} 13.204$, de 2015). Diário Oficial da União, Brasília, 2014. Disponível em: http://www.planalto.gov.br/ccivil_03/_ato20112014/2014/lei/l13019.htm. Acesso em 30 jul. 2021.

BRASIL. Lei $n^{\circ} 13.935$, de 11 de dezembro de 2019. Dispõe sobre a prestação de serviços de psicologia e de serviço social nas redes públicas de educação básica. Diário Oficial da União, Brasília, 2019. Disponível em: http://www.planalto.gov.br/ccivil_03/_ato20192022/2019/lei/L13935.htm Acesso em: 20 fev. 2021.

CAMPOS, M. M. As organizações não governamentais e a educação pré-escolar. Cadernos de Pesquisa, São Paulo, n. 67, p. 17-22, nov. 1988.

CARREIRA, D.; PINTO, J. M. R. Custo Aluno-Qualidade Inicial: rumo à educação pública de qualidade no Brasil. São Paulo: Ed. Global; Campanha Nacional pelo Direito à Educação, 2007.

CHIUZULI, D. R. Efeitos da judicialização da educação infantil em creche: uma análise a partir do contexto do Município de Ribeirão Preto. 2020. Dissertação (Mestrado em Educação) - Universidade de São Paulo, Ribeirão Preto, 2020. 
Estratégias de Privatização da Educação Infantil em Ribeirão Preto e as Resistências

CORREA, B. A gestão da educação infantil em 12 municípios paulistas. FINEDUCA - Revista de Financiamento da Educação, v. 8, n. 2, 2018. Disponível em: https://seer.ufrgs.br/fine duca/article/view/78020. Acesso em: 21 mar. 2021.

COSTA, B. A.; BORGHI, R. F. O atendimento da educação infantil via conveniamento: um estudo das justificativas municipais. Atos de Pesquisa em Educação, Blumenau, FURB, v. 8, p. 1019-1032, 2013.

CURY, C. A. J. O Público e o privado na história da educação brasileira: concepções e práticas educativas. In: LOMBARDI, J. C.; JACOMELI, M. R. M.; SILVA, T. M. T. (Org.). O público e o privado na história da educação brasileira: concepções e práticas educativas. Campinas: Autores Associados; Histedbr; Unisal, 2005.

DOMICIANO, C. Cogestão, democratização e privatização de equipamentos públicos de educação infantil: conceitos em disputa. Educação, Santa Maria, v. 45, 2020. Disponível em: https://periodicos.ufsm.br/reveducacao/article/view/38644/pdf. Acesso em: 6 maio 2021.

DUARTE Nogueira, do PSDB, é eleito prefeito de Ribeirão Preto, SP. G1, São Paulo, 30 out. 2016. Disponivel em: http://g1.globo.com/sp/ribeirao-preto-franca/eleicoes/2016/noticia/2016/ 10/duarte-nogueira-do-psdb-e-eleito-prefeito-de-ribeirao-preto-sp.html. Acesso em: 15 mar. 2021.

FRANCO, D. S. As creches na educação paulistana (2002-2012). 2015. Tese (Doutorado em Educação) - Faculdade de Educação, Universidade Estadual de Campinas, Campinas, 2015. Disponível em: http://repositorio.unicamp.br/jspui/handle/REPOSIP/305012. Acesso em: 30 jul. 2021.

FRANCO, D. S.; DOMICIANO, C. A.; ADRIÃO, T. Privatização das creches em São Paulo e seus efeitos sobre a qualidade da oferta. Teoria e Prática da Educação, v. 22, p. 80-96, 2019. Disponível em: https://periodicos.uem.br/ojs/index.php/TeorPratEduc/article/ view/50491. Acesso em: 15 mar. 2021.

FRANCO, M. A C. Lidando pobremente com a pobreza. In: ROSEMBERG, F. (Org.). Creche. São Paulo: Cortez; FCC, 1989. p. 179-216.

GARCIA, T. Incidência do setor privado na dimensão da gestão educacional na educação básica. In: GARCIA, T; ADRIÃO, T. (Org.). Incidência do setor privado na dimensão da gestão educacional na Educação Básica: programas e atores (2005-2015). V. 1. Curitiba: CRV, 2018. p. 53-63. Disponível em: https://www.greppe.fe.unicamp.br/ptbr/producoes?pgsql_combine_filter_views=+garcia\&field_autor_value=\&field_tipo_value=Livr o. Acesso em: 6 maio 2021.

GARCIA, T.; ADRIÃO, T.; BORGHI, R. A Nova Gestão Pública e o contexto brasileiro. In: MARTINS, A. (Org.). Instituições educacionais: políticas, gestão e práticas profissionais. V. 1. Santos: Editora Leopoldianum; Universidade Católica de Santos, 2009. p. 9-23.

JOHANSEN, C. C. A interiorização da assistência à infância e a experiência do Asylo de Orphans Anália Franco em Ribeirão Preto (1901-1925). 2017. Dissertação (Mestrado em Educação) - Programa de Pós-Graduação em Educação, Universidade de São Paulo, Ribeirão Preto, 2017.

KUHLMANN JR., M. Infância e educação infantil: Uma abordagem histórica. Porto Alegre: Mediação, 1998. 
Estratégias de Privatização da Educação Infantil em Ribeirão Preto e as Resistências

KUHLMANN JR., M. Educando a infância brasileira. In: LOPES, E. M. T.; FARIA FILHO, L. M.; VEIGA, C. G. (Org.). 500 anos de educação no Brasil. Belo Horizonte: Autêntica, 2000. p. 469-496.

LABORATÓRIO DE DADOS EDUCACIONAIS. Site. Curitiba: Universidade Federal do Paraná, 2021. Disponível em: https://dadoseducacionais.c3sl.ufpr.br/\#l. Acesso em: 30 jul. 2021.

OLIVEIRA, J. S.; BORGHI, R. Arranjos institucionais entre o poder público municipal e instituições privadas para a oferta de vagas na educação infantil. Revista Brasileira de Estudos Pedagógicos (Impresso), v. 94, p. 151-167, 2013. Disponível em: https://www. scielo.br/scielo.php?pid=S217666812013000100008\&script=sci_abstract\&tIng=pt. Acesso em: 30 abr. 2021.

OLIVEIRA, J. S. O atendimento público e privado concessionário na educação infantil: um olhar sobre as condições de oferta. 2013. 198 f. Dissertação (Mestrado em Educação) Universidade Estadual Paulista Universidade Estadual Paulista, Instituto de Biociências de Rio Claro, Rio Claro, 2013.

PINTO, J. M. R. Dinheiro traz felicidade? A relação entre insumos e qualidade na educação. Archivos Analíticos de Políticas Educativas, v. 22, p. 19, 2014.

PINTO, J. M. R. A política de fundos no Brasil para o financiamento da educação e os desafios da equidade e qualidade. Propuesta Educativa (Online), v. 52, p. 24-40, 2019. Disponível em: https://www.scielo.br/scielo.php?pid=S010173302007000300012\&script=sci_abstrac t\&tlng=pt. Acesso em: 12 abr. 2021.

PINTO, J. M. R.; ALVES, T. O impacto financeiro da ampliação da obrigatoriedade escolar no contexto do FUNDEB. Educação e Realidade, Porto Alegre, v. 36, p. 605-624, 2011.

PURIFICAÇÃO, R. F. Gestão da educação infantil: uma análise da evolução das matrículas em Ribeirão Preto entre 2009 e 2014. Monografia (Graduação em Filosofia) - Faculdade de Filosofia Ciências e Letras de Ribeirão Preto, Universidade de São Paulo, Ribeirão Preto, 2017.

RIBEIRÃO PRETO. Ministério Público. Ata Síntese de Audiência. PAA 14.1149.0000022.2017. Ribeirão Preto, 18 ago. 2017.

RIBEIRÃO PRETO. Lei $n^{\circ}$ 14.370, de 26 de julho de 2019. Dispõe sobre a qualificação de entidades sem fins lucrativos como organizações sociais de educação, para atuarem na educação infantil, primeira etapa da educação básica, nas escolas especificas conforme relação, e dá outras providências. Diário Oficial do Município, Ribeirão Preto, 2019a. Disponível em: https://www.ribeiraopreto.sp.gov.br/legislacao-municipal/pesquisa/lei/39298. Acesso em: 30 jul. 2021.

RIBEIRÃO PRETO. Prefeitura Municipal de Ribeirão Preto. Secretaria Municipal de Educação. Referencial Curricular da Rede Municipal de Ribeirão Preto. 2019b. p. 473. Disponível em: https://www.ribeiraopreto.sp.gov.br/files/seducacao/pdf/referencialcurricular.pdf. Acesso em: 2 abr. 2021.

RIBEIRÃO PRETO. Edital de chamamento público $n^{\circ}$ 01/2020: seleção de Organizações da sociedade Civil. OSC 2020. Disponível em: http://www.ribeiraopreto.sp.gov.br/f iles/seducacao/pdf/202001-edital-chamamento-atualizado.pdf. Acesso em: 22 fev. 2021. 
Estratégias de Privatização da Educação Infantil em Ribeirão Preto e as Resistências

RIBEIRÃO PRETO. Comunicado edital de chamamento $n^{\circ}$ 01/2020. Ribeirão Preto, 2021a. Disponível em: https://www.ribeiraopreto.sp.gov.br/files/seducacao/terceiro/ts-nulidade.pdf. Acesso em: 4 abr. 2021.

RIBEIRÃO PRETO. Parceria com a Prefeitura Municipal em novas unidades escolares. Ribeirão Preto, 2021b. Disponível em: https://www.ribeiraopreto.sp.gov.br/files/seducacao/ terceiro/ts-convite.pdf. Acesso em: 3 abr. 2021.

RIBEIRÃO PRETO. Conselho Municipal de Educação. Relatório da Comissão de Estudos sobre parcerias com o $3^{\circ}$ setor. Aprovado na $4^{\text {a }}$ Sessão Extraordinária do CME realizada em dia 24/03/2021. Ribeirão Preto, 2021c.

RIBEIRÃO PRETO. Secretaria de Educação. Parcerias com o Terceiro Setor-Portal. Ribeirão Preto, 2021d. Disponível em: https://www.ribeiraopreto.sp.gov.br/portal/educacao/ parcerias-com-o-terceiro-setor. Acesso em: 15 mar. 2021.

ROCHA, L. P. Atendimento Educacional em Creches Conveniadas: Estudo sobre oferta de vagas no município de Ribeirão Preto. 2015. 152 f. Dissertação (Mestrado em Educação) Faculdade de Filosofia Ciências e Letras de Ribeirão Preto, Universidade de São Paulo, 2015.

ROSEMBERG, F. Educação infantil pós-FUNDEB: avanços e tensões. In: SEMINÁRIO EDUCAR NA INFÂNCIA: PERSPECTIVAS HISTÓRICO-SOCIAIS, 2007, Curitiba. Mimeo. Curitiba, ago. 2007. Disponível em: http://www.diversidadeducainfantil.org.br/PDF/E duca $\%$ C3\%A7\%C3\%A30\%20infantil\%20p\%C3\%B3s-FUNDEB\%20avan\%C3\%A7os \%20e\% 20tens\%C3\%B5es\%20-\%20F\%C3\%BAlvia\%20Rosemberg.pdf. Acesso em: 25 mar. 2020.

SUSIN, M. O. K. O estatal e o público não-estatal: onde está a educação infantil comunitária em Porto Alegre? In: ADRIÃO, T.; PERONI, V. Público e privado na educação: novos elementos para o debate. São Paulo: Xamã, 2008. p. 67-78.

Bianca Correa é professora do curso de Pedagogia e da Programa de Pós-Graduação em Educação da FFCLRP-USP

ORCID: https://orcid.org/0000-0003-1906-8729

E-mail: biancacorrea@ffclrp.usp.br

José Marcelino de Rezende Pinto é professor do curso de Pedagogia e da Programa de Pós-Graduação em Educação da FFCLRP-USP.

ORCID: https://orcid.org/0000-0001-8355-2561

E-mail: jmrpinto@ffclrp.usp.br

Teise de Oliveira Guaranha Garcia é professora do curso de Pedagogia e da Programa de Pós-Graduação em Educação da FFCLRP-USP

ORCID: https://orcid.org/0000-0003-4351-3159

E-mail: teise@ffclrp.usp.br 